\title{
Carotid blowout syndrome: modern trends in management
}

This article was published in the following Dove Press journal: Cancer Management and Research

\section{Carlos Suárez, 1,2,* Verónica \\ Fernández-Alvarez, ${ }^{3, *}$ Marc Hamoir, ${ }^{4}$ William M Mendenhall, ${ }^{5}$ Primoz Strojan, ${ }^{6}$ Miquel Quer, ${ }^{7}$ Carl E Silver, ${ }^{8}$ Juan $\mathrm{P}$ Rodrigo, $1,2,9$ Alessandra Rinaldo, ${ }^{10}$ Alfio Ferlito ${ }^{11}$}

'Head \& Neck Cancer Laboratory, Instituto de Investigación Sanitaria del Principado de Asturias, Oviedo, Spain; ${ }^{2} \mathrm{Head} \&$ Neck Cancer Laboratory, Instituto Universitario de Oncología del Principado de Asturias, CIBERONC, University of Oviedo, Oviedo, Spain; ${ }^{3}$ Department of Vascular Surgery, Hospital Universitario de Cabueñes, Gijón, Spain; ${ }^{4}$ Department of Head and Neck Surgery, Head and Neck Oncology Program, King Albert II Cancer Institute, St Luc University Hospital, Brussels, Belgium; ${ }^{5}$ Department of Radiation Oncology, University of Florida, Gainesville, FL, USA; ' Department of Radiation Oncology, Institute of Oncology, Ljubljana, Slovenia; ${ }^{7}$ Department of Otolaryngology, Hospital Santa Creu i Sant Pau, Barcelona, Spain; ${ }^{8}$ Department of Surgery, University of Arizona, Phoenix, AZ, USA; ' Department of Otolaryngology, Hospital Universitario Central de Asturias, Oviedo, Spain; 10University of Udine School of Medicine, Udine, Italy; "International Head and Neck Scientific Group Padua, Italy

*These authors contributed equally to this work

Correspondence: Carlos Suárez Instituto de Investigación Sanitaria del Principado de Asturias, Avenida de Roma $\mathrm{s} / \mathrm{n}, 3301 \mathrm{I}$ Oviedo, Spain

Tel +3498524 4845

Email csuareznieto@gmail.com

\begin{abstract}
Carotid blowout syndrome (CBS) refers to rupture of the carotid artery and is an uncommon complication of head and neck cancer that can be rapidly fatal without prompt diagnosis and intervention. CBS develops when a damaged arterial wall cannot sustain its integrity against the patient's blood pressure, mainly in patients who have undergone surgical procedures and radiotherapy due to cancer of the head and neck, or have been reirradiated for a recurrent or second primary tumor in the neck. Among patients irradiated prior to surgery, CBS is usually a result of wound breakdown, pharyngocutaneous fistula and infection. This complication has often been fatal in the past, but at the present time, early diagnosis and modern technology applied to its management have decreased morbidity and mortality rates. In addition to analysis of the causes and consequences of CBS, the purpose of this paper is to critically review methods for early diagnosis of this complication and establish individualized treatment based on endovascular procedures for each patient.
\end{abstract}

Keywords: carotid blowout, head and neck cancer, reirradiation, surgery, covered stents, embolization

\section{Introduction}

Carotid blowout syndrome (CBS) is an uncommon but dreaded complication that occurs in patients treated for head and neck cancer. CBS is the result of necrosis of the arterial wall, which can occur following resection of head and neck cancer patients, after reirradiation for a recurrent or second primary tumor, by direct tumor invasion of the carotid artery wall or by a combination of these factors.

CBS may be categorized into three types that may involve the common carotid artery (CCA) and the internal carotid artery (ICA). Threatened (type I) CBS is characterized by carotid artery exposure found on examination or imaging (ie, air surrounding the vessel, adjacent abscess or tumor associated with a fistula) or by areas of arterial wall disruption found on vascular imaging studies. Impending blowouts (type II) are bleeding episodes ("sentinel bleeding") that can be resolved temporarily with pressure and wound packing. Carotid system hemorrhage (type III) is rapidly fatal, especially when it occurs outside the hospital setting. Bleeding can occur through skin or mucosa, possibly causing airway compromise. Identification of the early stages and prevention of type III CBS is crucial because patients with CBS who undergo therapy before the development of major hemorrhage have been shown to have a lower complication rate and better survival than do those who wait until major hemorrhage develops. ${ }^{1}$ 
In addition to study of the causes and the mortality/morbidity of CBS, the purpose of this paper is to review the new methods of diagnosis of CBS at an early stage and to establish individualized treatments such as endovascular repair of the carotid artery with covered stents or endovascular occlusion according to the characteristics of each patient.

\section{CBS after head and neck surgery Incidence}

Rupture of the carotid artery in a patient who has undergone major oncologic head and neck surgery is occasionally the unfortunate conclusion of a series of postoperative complications. The overall incidence of CBS in major oncological surgery of head and neck ranges between $3 \%$ and $4.5 \%{ }^{2-7}$ When patients who have previously been irradiated are analyzed separately; the CBS rate increases to $4.5 \%-21.1 \%,{ }^{8-14}$ while in radiotherapy naive patients, the CBS rate is only $0 \%-2.4 \%$ (Table 1). ${ }^{8-15}$ Planned preoperative radiotherapy at moderate doses ( $<45$ Gy) minimally increases the incidence of CBS, as reported in historical series $(2.7 \%-3 \%){ }^{16,17}$ According to Macdonald et al, in patients with head and neck cancers, previous irradiation increases the risk of CBS by 7.6 -fold. ${ }^{18}$
In general, prior radiotherapy has been administered in $80 \%-90 \%$ of patients with CBS. $2,3,5,6,12,19,20$

Carotid rupture occurs predominantly in the CCA near the bifurcation ( $60 \%-70 \%$ of the cases) and in a much smaller proportion in the ICA. ${ }^{20-22}$ Carotid rupture usually occurs $10-40$ days after surgery. In some patients, the hemorrhage may be delayed more than $2-3$ months after resection. ${ }^{19,23}$ The rupture site often occurs in a segment of arteriosclerotic change with stenosis. ${ }^{24}$ Bilateral, CBS is extremely rare, and encountered in only $2 \%$ of a cohort of 140 patients who experienced CBS. ${ }^{20}$

Liang et al reported that $68 \%$ of patients were present with acute hemorrhage, $24 \%$ with impending bleed and $8 \%$ with threatened bleed. ${ }^{22}$ Similar results were observed in the Powitzky et al series of 140 cases, which reported incidences of $60 \%, 53 \%$ and $23 \%$, respectively, with some of the patients with CBS type 1 and 2 subsequently progressing to CBS type $3 .^{20}$

\section{Predisposing factors for CBS}

Previous radiotherapy with curative intent is the main predisposing factor for the development of CBS after salvage

Table I Postsurgical CBS

\begin{tabular}{|c|c|c|c|c|c|c|}
\hline Study & $\begin{array}{l}\text { No. of } \\
\text { patients }\end{array}$ & $\begin{array}{l}\text { Previous } \\
\text { RT }\end{array}$ & $\begin{array}{l}\text { No. of } \\
\text { CBS }\end{array}$ & Mortality & Stroke & $\begin{array}{l}\text { Survival } \\
>\text { I months }\end{array}$ \\
\hline McCoy and Barsocchini ${ }^{6}$ & 93 & $3(75 \%)$ & $4(4.3 \%)$ & I (25\%) & 0 & 0 \\
\hline Joseph and Shumrick ${ }^{8}$ & 46 & No & 0 & & & \\
\hline Joseph and Shumrick ${ }^{8}$ & 57 & Yes & $12(21.1 \%)$ & $8(66.6 \%)$ & 2 & 2 \\
\hline Ketcham and Hoye ${ }^{5}$ & 574 & $16(84 \%)$ & $19(3 \%)$ & $3(15.8 \%)$ & - & 16 \\
\hline Curutchet et al $^{9}$ & 123 & No & $3(2.4 \%)$ & I (33.3\%) & 0 & 2 \\
\hline Curutchet et $\mathrm{al}^{9}$ & 78 & Yes & II (I4.1\%) & $4(36.4 \%)$ & 5 & 2 \\
\hline Yim et al $^{10}$ & 48 & No & 0 & & & \\
\hline Yim et al $^{10}$ & 84 & Yes & $4(4.8 \%)$ & - & - & - \\
\hline Martinez et $\mathrm{al}^{4}$ & 365 & - & II (3\%) & $7(63.6 \%)$ & - & 4 \\
\hline Shumrick $^{3}$ & 333 & $10(77 \%)$ & $13(3.8 \%)$ & $8(61.5 \%)$ & 3 & 2 \\
\hline Stell' & 210 & No & 0 & & & \\
\hline Stell ${ }^{\prime \prime}$ & 70 & Yes & $9(13 \%)$ & $7(77.8 \%)$ & $\mathrm{I}$ & 1 \\
\hline Leikensohn et $\mathrm{al}^{2}$ & 393 & $18(90 \%)$ & $20(4.5 \%)$ & $5(25 \%)$ & 5 & 10 \\
\hline Maran et $\mathrm{al}^{12}$ & 227 & No & $3(1.1 \%)$ & $3(100 \%)$ & 0 & 0 \\
\hline Maran et $\mathrm{al}^{12}$ & 167 & Yes & $14(8.4 \%)$ & $14(100 \%)$ & 0 & 0 \\
\hline Herranz et al ${ }^{15}$ & $47 I$ & No & $3(0.6 \%)$ & I (33.3\%) & 0 & 1 \\
\hline Marchetta et $\mathrm{al}^{13}$ & 81 & No & 0 & & & \\
\hline Marchetta et $\mathrm{al}^{13}$ & 83 & Yes & $6(7 \%)$ & $2(33.3 \%)$ & 0 & 4 \\
\hline Krause et al ${ }^{17}$ & 193 & $\begin{array}{l}\text { RT } \\
\text { preoperatory }\end{array}$ & $5(3 \%)$ & I (20\%) & 0 & 4 \\
\hline Sarkar et al $^{14}$ & 152 & No & $\mathrm{I}(0.7 \%)$ & 0 & 1 & 1 \\
\hline Sarkar et al ${ }^{14}$ & 90 & Yes & $4(4.4 \%)$ & $3(75 \%)$ & 0 & 1 \\
\hline Lu et $\mathrm{al}^{7}$ & 3,504 & - & $45^{\mathrm{a}}(1.3 \%)$ & I I (24.4\%) & - & $34(76 \%)$ \\
\hline Chen et $\mathrm{al}^{25}$ & 301 & No & I $(0.3 \%)$ & - & - & - \\
\hline Chen et $\mathrm{al}^{25}$ & 2,289 & Yes & $101(4.4 \%)$ & $34(33.3 \%)$ & 13 & 68 \\
\hline
\end{tabular}

Note: ${ }^{a}$ Only acute CBS.

Abbreviation: CBS, carotid blowout syndrome. 
surgery. According to Chen et al, patients who received a total radiation dose $>70$ Gy to the neck incurred a near 14-fold increased risk of developing CBS. ${ }^{25}$ In a series of 63 patients treated at the Memorial Sloan-Kettering Cancer Center (MSKCC) NY, USA between 1961 and 1974 with postoperative CBS, only seven patients had no history of previous radiation therapy. This confirms that radiotherapy is the main predisposing factor for the development of CBS. ${ }^{19}$ The adventitial layer has been shown to provide about $80 \%$ of the blood supply to the remaining walls of the carotid artery. Free radicals produced by radiation cause thrombosis and obliteration of the adventitial vasa vasorum, adventitial fibrosis, premature atherosclerosis and weakening of the arterial wall. The carotid artery ruptures because its wall is damaged by ischemia, as it receives most of its blood supply from the adventitia. The weakness of the arterial wall can lead to the formation of pseudoaneurysms that have been reported even 2-20 years after radical neck dissection and irradiation. ${ }^{26}$ Some patients may incur spontaneous radiationinduced necrosis of the arterial wall.

Neck dissection with stripping of the carotid sheath may also compromise the nutrition of the carotid artery. Radical neck dissection renders the carotid artery more vulnerable to rupture due to the lack of supporting healthy tissues. This could explain an eightfold increased risk of developing carotid blowout in patients who had a radical neck dissection when compared with those who did not undergo neck dissection. $^{25}$

Bacterial infections may also induce vasa vasorum thrombosis and arterial wall injury, creating an increased sensitivity to the effects of inflammatory mediators in contaminated wounds. In addition, surgical site infection inevitably causes tissue necrosis and pharyngocutaneous fistula formation. ${ }^{25}$ In patients with a fistula, direct contact of the arterial wall with saliva is of particular concern because of its tryptic enzyme activity. If the carotid artery is exposed to salivary flow, it may be subjected to desiccation and digestion of its wall by salivary enzymes. In the aforementioned Powitzky et al series, $38 \%$ of patients who developed CBS had infection, $40 \%$ had a fistula and $55 \%$ had soft tissue necrosis. ${ }^{20}$ In the MSKCC series, $61.9 \%$ of the 63 patients developed substantial necrosis of cervical skin flaps, and $63.5 \%$ had fistula. ${ }^{19}$ Only five patients had neither of these complications diagnosed before hemorrhage but had either undetected wound sepsis or mucosal defects under intact skin. ${ }^{19}$

The comparative effects of loss of adventitia and vasa vasorum, desiccation, fistula and infection have been studied experimentally in $\operatorname{dogs} .^{27}$ If the adventitia was preserved, while simultaneously leaving the vessel exposed in an open wound, there were no carotid ruptures despite the existence of a fistula, infection or desiccation; the adventitia was covered with granulation tissue. When the adventitia was resected, infection was the most important factor for arterial rupture, leading to inflammation and gradual erosion of the arterial wall. In the absence of adventitia, desiccation and fistula played a less important role than infection in the development of CBS.

\section{Recurrent CBS}

Recurrent CBS is defined as either a repeated episode of selflimited or uncontrollable bleeding that occurs in the same arterial segment or territory that previously had been treated, a few hours or days after completion of therapy for a previous episode of CBS, or bleeding from a newly exposed portion of the carotid system occurring any time after therapy for a previous episode of CBS was completed. The first category could be considered as treatment failure, whereas the second one could be classified as progressive disease. Patients belonging to the latter group develop independent episodes of hemorrhagic recurrences. It was observed that $65 \%$ of the recurrent events were attributable to progressive disease, and the rest treatment failures from a previously treated arterial pseudoaneurysm. ${ }^{28}$ Liang et al estimated that recurrent bleeding risk at 30 days and 6 months are $24 \%$ and 34\%, respectively. ${ }^{22}$ According to Chaloupka et al, recurrent episodes of CBS could be attributed to one or more of the following putative etiologic factors: 1) surgical wound dehiscence, 2) musculocutaneous flap necrosis, 3) radiation-induced arteriopathy and 4) tumor invasion of a major arterial segment or tumor re-growth and invasion. Recurrent CBS assigned to progressive disease could be categorized into bleeding from vasculature that was either ipsilateral or contralateral to the first episode of CBS. ${ }^{28}$

\section{Prevention of CBS}

In patients undergoing salvage surgery, protection of the carotid artery with local muscular flaps (sternocleidomastoid or levator scapulae muscles) has not been associated with a significant reduction in CBS compared with no protection, ${ }^{16}$ probably because these tissues are poorly vascularized. However, other authors have reported this maneuver as having a positive effect. ${ }^{29}$ More recently, in heavily irradiated patients, many surgeons consider the option of covering the operative area with distant myocutaneous or fasciocutaneous flaps with good blood supply. Cordova et al compared 96 patients with head and neck cancer treated with salvage surgery (ie, 
radical neck dissection and microsurgical reconstruction of the tumor site) after radiotherapy failure, with 21 prospectively recruited patients in whom an anterolateral thigh and vastus lateralis muscle flap was used to simultaneously reconstruct the tumor site and a sternocleidomastoid muscle flap employed to fill dead space and protect the carotid artery. ${ }^{30}$ The rate of complications was higher in the historical group: CBS occurred in $4.1 \%$ and orocutaneous fistulas in $11.5 \%$ of patients; $5.2 \%$ of patients required major salvage surgery for a wound complication. In the prospective cohort, no CBS or orocutaneous fistula occurred and no major salvage surgical procedures were needed.

\section{CBS after reirradiation of a recurrent tumor}

\section{Incidence}

In patients previously treated with radiation therapy to the neck, reirradiation may be a feasible option for selected patients who have no other curative surgical treatment options available. Depending on the location and extent of the tumor, reirradiation may be accomplished with conventionally fractionated external beam radiotherapy, intensity-modulated radiation therapy, intraoperative radiotherapy, stereotactic radiosurgery (SRS), hypofractionated stereotactic radiotherapy (hSRT) or brachytherapy.
Generally, the incidence of CBS in reirradiated recurrent tumors of the head and neck ranges between $0 \%$ and $17 \%$ (Table 2). ${ }^{31-52}$ After conventionally fractionated reirradiation using less sophisticated RT techniques, associated or not associated with chemotherapy, bleeding rates of $0 \%-7 \%$ were reported, ${ }^{31-35,39-57}$ whereas in intensity-modulated radiation therapy series bleeding rates were lower, $0 \%-2.4 \% .{ }^{38}$ However, several SRS and hSRT series have reported higher rates $(0 \%-17 \%)$ of bleeding (Table 2$).{ }^{48-52}$ Notably, only patients with tumor invasion of $>180^{\circ}$ of the carotid circumference develop CBS. CBS is caused not only by the high dose of radiation but also by the weakening of the arterial wall by direct tumor invasion with inflammatory process. ${ }^{51,58}$

In a systematic review, McDonald et al reported a total of 41 patients with CBS among 1,554 patients receiving reirradiation with external beam radiotherapy, constituting a crude rate of $2.6 \% .{ }^{53}$ The median time to CBS was 7.5 months, ranging from 0 months (acute $\mathrm{CBS}$, occurring during reirradiation) to 54 months from the start of reirradiation. ${ }^{53}$ A similar median interval between reirradiation with hSRT and CBS onset ( 5 months) has been reported. ${ }^{50}$ In patients treated with continuous course RT at 1.8-2 Gy per daily fractions or 1.2 Gy per twice daily fractions, the rate of CBS was $1.3 \%$, compared with $4.5 \%$ in patients treated with 1.5 Gy twice daily on alternating weeks or with delayed accelerated hyperfractionation. ${ }^{53}$

Table 2 Salvage reirradiaton and CBS

\begin{tabular}{|c|c|c|c|c|c|}
\hline Study & No. of patients & RT technique & No. of CBS & Mortality & Survival $>$ I months \\
\hline Dawson et $\mathrm{al}^{31}$ & 40 & 3D-CRT & $\mathrm{I}(2.5 \%)$ & 0 & 1 \\
\hline Kasperts et al ${ }^{32}$ & 39 & 3D-CRT & 0 & & \\
\hline Tanvetyanon et $\mathrm{al}^{33}$ & 103 & Various $\pm \mathrm{Ch}$ & $\mathrm{I}(\mathrm{I} \%)$ & 1 & 0 \\
\hline Rate et $\mathrm{a}^{34}$ & 47 & IORT & $\mathrm{I}(2.1 \%)$ & $\mathrm{I}$ & 0 \\
\hline Stevens et $\mathrm{al}^{35}$ & 100 & EBRT \pm brachy & $4(4 \%)$ & 4 & 0 \\
\hline Duprez et $\mathrm{al}^{36}$ & 84 & IMRT & $2(2.4 \%)$ & 2 & 0 \\
\hline Lee et $\mathrm{al}^{37}$ & 105 & IMRT $\pm \mathrm{Ch}$ & 0 & & \\
\hline Sulman et $\mathrm{al}^{38}$ & 74 & $\mathrm{IMRT} \pm \mathrm{Ch}$ & 0 & & \\
\hline Watkins et $\mathrm{al}^{39}$ & 39 & $\mathrm{Ch} / \mathrm{Rt}$ & $2(5.1 \%)$ & 1 & 1 \\
\hline De Crevoisier et $\mathrm{al}^{40}$ & 169 & $\mathrm{Ch} / \mathrm{Rt}$ & $5(2.9 \%)$ & 5 & 0 \\
\hline Salama et $\mathrm{al}^{41}$ & 115 & $\mathrm{Ch} / \mathrm{Rt}$ & $6(5.2 \%)$ & 5 & 1 \\
\hline Janot et a $\left.\right|^{42}$ & 60 & $\mathrm{Ch} / \mathrm{Rt}$ & $\mathrm{I}(\mathrm{I} .7 \%)$ & 1 & 0 \\
\hline Kramer et $\mathrm{al}^{43}$ & 38 & $\mathrm{Ch} / \mathrm{Rt}$ & $\mathrm{I}(2.7 \%)$ & 1 & 0 \\
\hline Langer et $\mathrm{al}^{44}$ & 83 & $\mathrm{Ch} / \mathrm{Rt}$ & $2(2.4 \%)$ & 2 & 0 \\
\hline Spencer et $\mathrm{al}^{45}$ & 79 & $\mathrm{Ch} / \mathrm{Rt}$ & $2(2.5 \%)$ & 2 & 0 \\
\hline Hehr et al ${ }^{46}$ & 27 & $\mathrm{Ch} / \mathrm{Rt}$ & $2(7 \%)$ & 2 & 0 \\
\hline Iseli et al ${ }^{47}$ & 87 & $\mathrm{Ch} / \mathrm{Rt}$ & $5(5.7 \%)$ & $\mathrm{I}$ & 3 \\
\hline Lartigau et $\mathrm{al}^{48}$ & 56 & SBRT & $\mathrm{I}(\mathrm{I} .8 \%)$ & $\mathrm{I}$ & 0 \\
\hline Cengiz et $\mathrm{al}^{49}$ & 46 & SBRT & $8(17 \%)$ & 7 & 1 \\
\hline Yamazaki et al ${ }^{50}$ & 381 & SBRT & $32(8 \%)$ & 22 & 10 \\
\hline Yazici et al ${ }^{51}$ & 75 & SBRT & II (I4.7\%) & 8 & 3 \\
\hline Vargo et $\mathrm{al}^{52}$ & 48 & SBRT & 0 & & \\
\hline
\end{tabular}

Abbreviations: 3D-CRT, three-dimensional conformal radiotherapy; CBS, Carotid blowout syndrome; $\mathrm{Ch} / \mathrm{Rt}$, chemoradiotherapy; EBRT, external beam radiotherapy; IMRT, intensity-modulated radiotherapy; IORT, intraoperative radiotherapy; SBRT, stereotactic body radiotherapy. 
Generally, the median cumulative dose of the two radiotherapy courses varies from 110 to $130 \mathrm{~Gy} .{ }^{31,32,35,37,40,54-56}$ Cumulative doses $>130$ Gy show a higher rate of CBS and other acute and delayed toxic effects than lower doses. Thus, Salama et al have reported that the median repeated radiation dose for the six patients who experienced carotid hemorrhage was $74 \mathrm{~Gy}$, and the median lifetime dose of radiation was 139 Gy. ${ }^{41}$ Similar results have been reported by Duprez et al, which indicates that the cumulative dose of most of the patients who develop a CBS is $\sim 140 \mathrm{~Gy}{ }^{36}$

Sequential bilateral acute CBS is a rare condition described by Liu et al in seven patients $(2.5 \%$ of 285 CBS patients) long after reirradiation for head and neck cancer. ${ }^{57}$ The first bleeding episode occurred at a mean interval of 12.4 \pm 4.5 years (range, $7-19$ years) after the second course of radiotherapy. In all seven patients, at the time of the first CBS, the contralateral carotid arteries were normal or stenotic on angiography: the contralateral CBS occurred within 3 months after the first CCA/ICA episode. One patient experienced a third episode of bleeding from a branch of the external carotid artery (ECA) 6.8 years later.

\section{Predisposing factors for CBS}

Radiation-induced necrosis frequently precedes bleeding, and it is sometimes difficult to differentiate recurrence with or without infection from radionecrosis without recurrence. Patients can develop a pharyngocutaneous fistula as a result of rapid tumor shrinkage, and fatal hemorrhage can occur from a compromised artery eroded by residual tumor close to the fistula. ${ }^{46}$

The role of surgery prior to reirradiation in the development of a CBS has been studied, but its effect does not seem relevant. Thus, among 917 patients treated without salvage surgery before reirradiation, the CBS rate was $3.3 \%$, whereas in 294 patients who received salvage surgery before reirradiation, the CBS rate was $2 \% .{ }^{53}$ Similar results have been reported by Iseli et al. ${ }^{47}$ Other studies have not reported statistically significant differences in the rate of CBS between patients treated with or without concurrent chemotherapy. ${ }^{53}$

As stated, hSRT and SRS are accompanied by a higher rate of CBS, which is most probably related to the increased biological efficacy of higher radiation doses per fraction. Bleeding is not statistically significantly related to tumor volume, response to treatment, sex or time elapsed between hSRT and previous radiotherapy. Several studies have shown that only patients with tumor encasement of $>180^{\circ}$ of the carotid circumference are likely to develop CBS. ${ }^{49,51,58}$ Direct infiltration of the carotid wall by neighboring tumor with accompanied inflammatory reaction is responsible for a higher irradiation dose to carotid artery while at the same time weakening the wall of carotid artery. However, it has been observed that the irradiation fractionation schedule may not influence the development of CBS. Thus, in patients who were treated daily, the incidence of CBS was $16 \%$, whereas $12.5 \%$ of patients who were treated every other day developed a CBS. ${ }^{51}$ In this series, CBS did not occur in any of the patients with a maximum carotid artery radiation dose $<34$ Gy (delivered in 3-6 fractions, median 5 fractions).

Finally, Yamazaki et al have developed a CBS index for classifying the risk groups and for estimation of the CBS risk before reirradiation. ${ }^{58}$ The CBS index was constructed by summation of different risk factors as follows: carotid encasement $>180^{\circ}$, presence of ulceration and lymph node area irradiation. Risk factor groups 0-2 were associated with CBS-free survival rates of $100 \%, 95 \%$ and $84 \%$ at 12 months, respectively, whereas the risk group 3 had a CBS-free survival rate of $25 \%$ at 6 months.

Recently, some cases of CBS have been reported in patients treated with primary chemoradiotherapy without prior irradiation who did not have the usual predisposing factors. ${ }^{59}$ In those cases, a residual non-tumorous ulceration was present along the lateral wall of the hypopharynx and the ulceration reached the vascular axis, precipitating CBS. Thus, residual non-tumorous ulceration of the lateral wall of the hypopharynx after chemoradiotherapy should be considered with the utmost caution.

\section{Mortality and morbidity}

Carotid rupture in the setting of reirradiation in nearly all instances results in death of the patient because of massive hemorrhages in the pharynx or elsewhere which cannot be treated expeditiously in an emergency unit. In a systematic review by McDonald et al, 29 of $38 \mathrm{CBS}(76 \%)$ were fatal. ${ }^{53}$ Yamazaki et al have reported that almost all CBS-related deaths occurred within 1 month after CBS onset. ${ }^{50}$ Survival rates at 1 month and 1 year after CBS were 34\% and 31\%, respectively. Older age, skin invasion and signs of necrosis/ infection were all identified as statistically significant risk factors after CBS.

\section{Management of CBS Ligature of the CCA or ICA}

Emergency open surgical ligations of the CCA or ICA without testing the collateral cerebral circulation are associated with a higher neurological complication rate when compared with patients receiving endovascular procedures first. ${ }^{7}$ Cur- 
rently, emergency open surgery is not preferred due to poor outcome and is usually complicated by local wound infection, flap necrosis, hemodynamic instability, profound hypotension, global cerebral ischemia and consumptive coagulopathy secondary to extreme blood loss. ${ }^{60}$ Surgical management of CBS is usually difficult because the procedures must often be performed in previously irradiated or infected fields. Recently, the need to ligate the CCA/ICA by open surgical approach has been reported in $7 \%-32 \%$ of patients with CBS. ${ }^{20,22,25}$ Selection criteria for carotid ligature include patients with recently performed radical neck dissection and extensive areas of skin and soft tissue necrosis when the CBS occurs, whereas patients with no recent or open wound in the neck are preferably treated with endovascular procedures. $^{25}$

\section{Mortality and morbidity}

Since the 1960s, most reports of recently performed ligature of the carotid artery have shown relatively high rates of mortality and neurological morbidity. The mortality rates of postsurgical CBS reported in the literature ranged from $15 \%$ to $100 \%$, with an average rate of around $50 \%$ (Table 1). ${ }^{2-6,8,9,11-15,17,19,25,61}$

In a series of 77 patients with CBS, Razack et al reported that $54 \%(42 / 77)$ of patients died of hemorrhage or neurological deficits before leaving the hospital; $30 \%$ $(23 / 77)$ died due to tumor progression after a survival of 12-18 months; 9\% (7/77) survived without deficits between 3 and 5 years and died from tumor recurrence and only $6.5 \%(5 / 77)$ survived more than 5 years without sequelae or evidence of tumor. ${ }^{21}$

In historical series, $\sim 10 \%-20 \%$ of patients had permanent neurological sequelae, and only $30 \%-40 \%$ of the patients who suffered a CBS had no sequelae (Table 1). 2,3,6,8,9,11-15,17,19,61,62

Blood pressure must be addressed aggressively and with proper resuscitation. The risk of morbidity associated with ligation increases significantly in the setting of hypotension, which is the most important predictor of a poor outcome in the acute treatment of CBS. ${ }^{63}$ Moore et al have shown in a series with 151 cases of CCA/ICA ligations, that 31 of 47 patients $(65.9 \%)$ who were hypotensive at the time of ligation exhibited a neurological deficit, and 27 of them $(57.4 \%)$ died. ${ }^{64}$ Among 104 not hypotensive patients, 28 exhibited permanent neurological injury (26.9\%) and 17 (16.3\%) died. ${ }^{64}$ Neurological sequelae can be delayed, occurring more than 8 hours after ligation, and their prevention with low-dose heparin has been advocated. ${ }^{2}$

\section{Prognostic factors}

Lu et al analyzed 45 patients who suffered from acute CBS, defined as acute and profuse hemorrhage, not self-limiting, over the carotid trunk. ${ }^{7}$ Successful management of acute CBS was defined as survival of the patient after the episode of more than 72 hours. Patients underwent open surgical ligation if radical neck dissection had been performed recently and wound healing was not complete. Open surgical treatment had a higher mortality rate than endovascular therapy. The mortality rates of endovascular therapy and surgical ligation were $10 \%$, and $28.6 \%$, respectively. ${ }^{7}$

Among the baseline characteristics, the site of the primary tumor, origin of bleeding, method of intervention and time to intervention were factors that most significantly differed between surviving and non-surviving patients. After 24 hours of CBS onset, a Glasgow Coma Scale score, the use of inotropic agents and neutrophil-to-lymphocyte ratio were found to significantly predict the outcome. Hemodynamic status was an important prognostic factor because it resulted in prolonged hypovolemic shock and severe vasoconstriction. This condition also induces multiorgan failure and general tissue ischemia. ${ }^{7}$ Multivariate logistic regression analyses revealed that bleeding from CCA was an independent factor for long-term survival.

\section{Indications for endovascular procedures}

Endovascular management with occlusion of the CCA/ICA has substantially improved outcomes when it is correctly indicated. . 57,82 However, this procedure can induce delayed cerebral ischemic complications resulting from an incomplete circle of Willis, thromboembolism arising from an acutely occluded carotid artery and/or delayed collateral failure. As an alternative, CBS can be managed by reconstructing the damaged artery with covered stents.

Thus, the indications for endovascular repair with covered stents are mostly for patients at risk of permanent carotid occlusion, such as incomplete circle of Willis, contralateral carotid severe stenosis or total occlusion, intolerance to a balloon occlusion test (BOT) or emergency status of the patient precluding an occlusion test. Even in patients with an open wound in the neck and fistula, in some circumstances, endovascular procedures are preferable.

Endovascular methods are well suited for the management of CBS of any etiology: salvage surgery in heavily irradiated patients, rupture after reirradiation for recurrent tumor or bleeding caused by direct carotid invasion of persistent or recurrent tumor. Palliative treatment of the latter has become 
the most frequent indication for endovascular techniques in some series. ${ }^{7,65,66}$

Embolization procedures have become the most frequently used endovascular method for management of CBS. Using the database of the Nationwide Inpatient Sample from the period 2003-2011, 1,218 patients underwent endovascular treatment for CBS in the USA. Of these, 1,080 patients (88.6\%) underwent embolization procedures and 138 patients (11.4\%) underwent carotid stenting. ${ }^{67}$ Powitzky et al analyzed 140 patients with CBS reported in the literature. ${ }^{20}$ Over $90 \%$ of initial and recurrent cases of CBS reported were treated with endovascular embolization (56\%) or stenting (36\%). Ligation (7\%) was rarely used for the primary management of CBS.

\section{Diagnostic angiography}

For patients who are hemodynamically stable, high-resolution digital subtraction angiography is performed using the transfemoral arterial approach to obtain a complete neuroangiogram of the supra-aortic arteries in order to identify the lesions. ${ }^{1,68,69}$

Arterial wall irregularity, luminal stenosis, pseudoaneurysm formation, arterial wall rupture and contrast leak are the main angiographic findings in patients with CBS. ${ }^{1,68,70}$

Chang et al classified the severity of the vascular injury, graded from 1 to 4 , according to the following findings: grade 1 is defined as no angiographic vascular disruption; grade 2 indicates a focal irregularity of the diseased carotid artery; grade 3 is defined as a pseudoaneurysm of the injured carotid artery and grade 4 indicates active extravasation from the ruptured artery. ${ }^{1,69}$

\section{Evaluation of tolerance to carotid occlusion}

The BOT identifies patients at risk of immediate ischemia from occlusion, but its sensitivity is controversial. ${ }^{71}$ A BOT may be performed in threatened $\mathrm{CBS}$ where a reconstructive approach of the CCA and/or ICA is not an option and the patient is hemodynamically stable and not bleeding profusely. A non-detachable balloon is positioned into the abnormal artery just proximal to the lesion and the balloon is carefully inflated. The neurological examination is repeated every $3-5$ minutes for a total test time of 20-30 minutes, after which the balloon is deflated. If the patient tolerates the test, permanent occlusion of the CCA or ICA can be considered.

However, in acute cases where patients have unstable vital signs or impaired consciousness, BOT is usually not possible. ${ }^{28,68,69}$ Then an angiogram of the contralateral carotid artery and the posterior circulation is required to check if the circle of Willis is complete and whether there is adequate collateral flow. ${ }^{68}$

\section{Endovascular occlusion}

The indications for endovascular occlusion are lesions involving the trunk of the ECA and also CCA or ICA lesions in patients in whom a BOT demonstrated that the vessel can be occluded without significant risk of brain ischemia. ${ }^{71}$ Endovascular occlusion includes permanent balloon occlusion, vascular plugs and embolization. Therapeutic permanent balloon occlusion can be performed in cases of pseudoaneurysm formation or extravasation, but is rarely used today. ${ }^{68}$

The Amplatzer Vascular Plug is a self-expanding cylindrical device of nitinol wire mesh. ${ }^{72}$ It is delivered through a guide catheter into the diseased vessel proximal to the lesion. It adjusts to the shape of the vessel resulting in vessel occlusion. Amplatzer Vascular Plug can be used as an alternative device for fast occlusion of extracranial carotids, especially in hemodynamically unstable patients and in large vessel occlusions.

Embolization can be performed through cross occlusion. It consists of deployment of embolic materials (microparticles, microcoils, injected acrylic adhesive or detachable balloon) through a micro/catheter from distal to the pathological lesion to its proximal extent. Another method of embolization is through proximal occlusion. It is used in cases where associated focal carotid stenosis or tortuosity prevents the microcatheter from crossing the lesion; thus, the embolic materials are placed in the CA proximal to the lesions. ${ }^{1}$

\section{Endovascular repair with covered stents}

Autogenous venous or arterial reconstructions have been proposed for the treatment of patients with invasion of the carotid system, but the urgent nature of the situation and the expected postoperative complications make it non-viable. ${ }^{1,68}$

Covered stents have been proposed to reduce the neurological morbidity associated with carotid occlusion, particularly in patients who cannot tolerate carotid artery sacrifice due to an incomplete circle of Willis. ${ }^{69,73,74}$

The first commercially available Food and Drug Administration approved device was the Boston Scientific Wallgraft. This self-expanding device is made of woven stainless steel with porous Dacron covering but this porosity makes it unsuitable for use in an acute bleeding situations such as CBS. ${ }^{75}$ Polytetrafluoroethylene-covered nitinol stent grafts (ie, Gore Viabahn and Bard Fluency) are the most frequently used devices today. ${ }^{69,75}$ They are delivered to traverse the 
damaged part of the artery to reconstruct the vascular wall. They are very flexible and have good conformability, achieving successful exclusion of the pseudoaneurysm with cessation of bleeding. Balloon angioplasty of the stent, to increase its diameter, may be necessary to ensure tight apposition of the graft to the carotid artery.

Patients undergoing reconstructive techniques of CBS require close clinical follow-up with interval computed tomographic angiography or duplex sonography to assess the patency of the stent grafts. Distal marginal stenosis is a common cause of stent graft occlusion, and inadequate coverage of the ongoing pathological lesion by the stent graft is a cause of re-bleeding that only early diagnosis can avoid. Another limitation of reconstructive techniques is the presence of infection and/or fistula. In case of infection, the rate of failure of reconstructive techniques is very high. ${ }^{1,71,86}$

Because any stent placed in the carotid artery serves as a nidus for platelet aggregation and formation of thrombus, a dual antiplatelet regimen with aspirin (324 mg) and clopidogrel $(75 \mathrm{mg})$ is recommended following stent placement during the first month. Later, this regimen is changed to aspirin (100 mg) for life-long use, although it may be unsuitable in patients with significant re-hemorrhage risk (Figure 1). ${ }^{1,74}$

\section{Complications of endovascular management}

Endovascular repair of CBS with covered stents in patients who have risk factors for neurological sequelae after embolization has reduced the rate of cerebrovascular accidents (Table 3). Stroke is still a frequent cause of death after CBS. Endovascular embolization of CBS is indeed associated with a cerebral ischemic insult in $8 \%-14 \%$ of the patients ${ }^{22,69,76}$ and even though patients at high risk of neurological sequelae are currently treated with covered stents, a cerebral infarction was still reported after such intervention in $15 \%-30 \%$ of patients. ${ }^{1,60,70}$

In the aforementioned review of the literature, Powitzky et al reported a higher risk of CBS recurrence with stent placement (44\%) compared with embolization therapy (10\%) or surgical ligation $(25 \%) .{ }^{20} \mathrm{~A}$ systematic review by Bond et al of 559 patients with CBS, including the ECA, revealed a rebleeding rate of $27 \%$ among all patients $-17 \%$ for patients treated with coils, and $34 \%$ for patients treated with covered stents. ${ }^{77}$ Other authors have also observed significantly lower rebleeding rates with embolization (11\%-21\%) compared with covered stents (25\%-85\%) (Table 3). ${ }^{1,22,28,69,70,73,78-86}$ Short- and long-term rebleeding after stent placement can occur from the stented carotid artery as a result of either

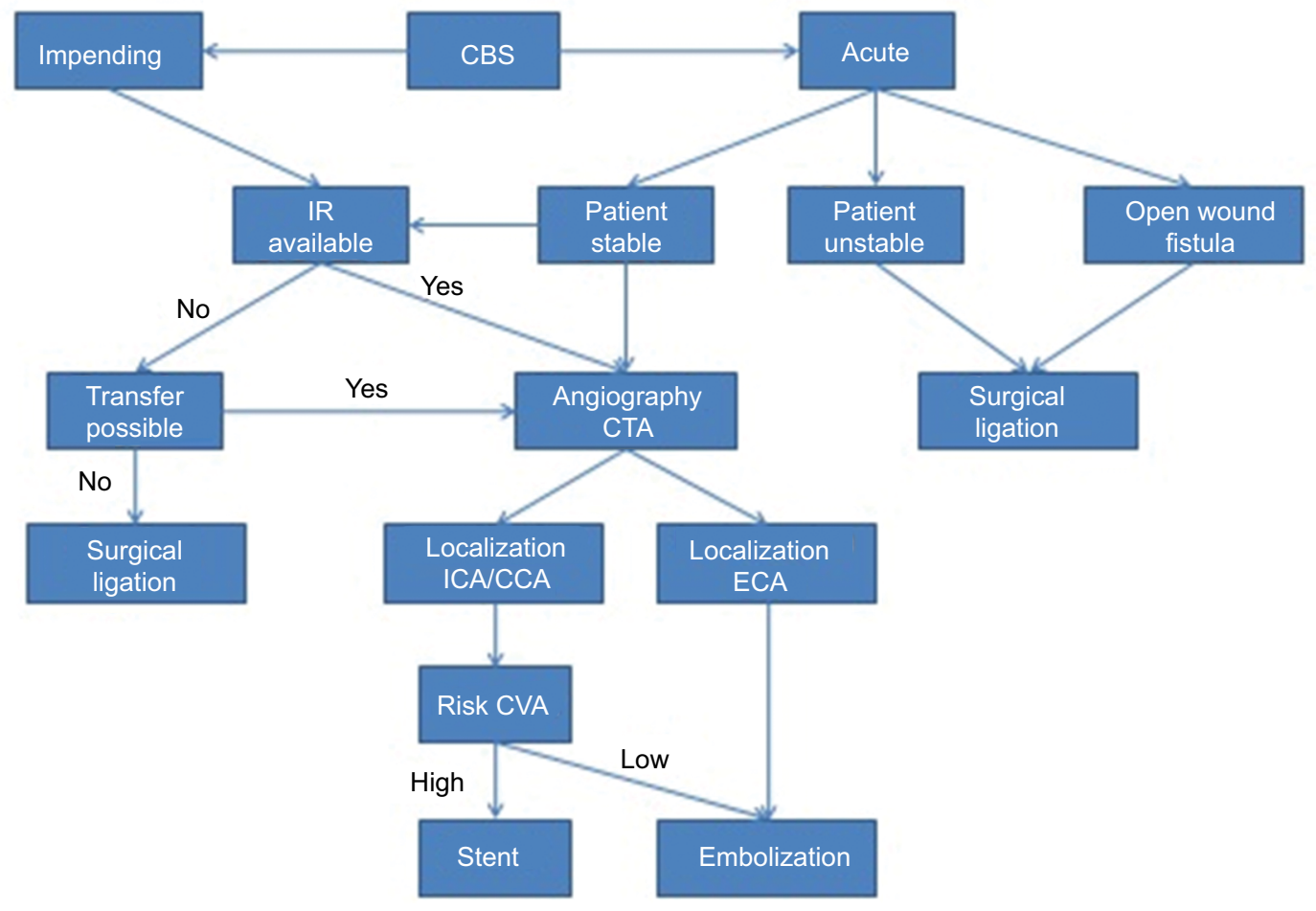

Figure I Management algorithm for CBS.

Abbreviations: CBS, carotid blowout syndrome; CCA, common carotid artery; ECA, external carotid artery; ICA, internal carotid artery; CTA, computed tomographic angiography; CVA, cerebrovascular accident; IR, interventional radiology. 
Table 3 Treatment and outcomes of CBS

\begin{tabular}{|c|c|c|c|c|c|c|c|c|c|}
\hline \multirow[t]{2}{*}{ Study } & \multirow{2}{*}{$\begin{array}{l}\text { No. of } \\
\text { patients }\end{array}$} & \multicolumn{2}{|c|}{ Treatment } & \multicolumn{2}{|c|}{ Compl stent } & \multicolumn{2}{|c|}{ Compl embol } & \multirow{2}{*}{$\begin{array}{l}\text { Mortality } \\
<\text { I months }\end{array}$} & \multirow{2}{*}{$\begin{array}{l}\text { Survival >I } \\
\text { year }\end{array}$} \\
\hline & & Stent & Emb & Rbl & Stroke & Rbl & Stroke & & \\
\hline Chang et $\mathrm{a}^{85}$ & 8 & 8 & 0 & 4 & 1 & - & - & 3 & 3 \\
\hline Liu et $\mathrm{a}^{57}$ & 13 & 2 & 11 & 1 & I & I & I & 3 & 2 \\
\hline Chen et $\mathrm{a}^{25}$ & 24 & 0 & 24 & - & - & 11 & 6 & 8 & - \\
\hline Shah et a ${ }^{86}$ & 10 & 10 & 0 & 3 & 1 & - & - & 3 & 2 \\
\hline Powitzky et $\mathrm{al}^{20}$ & 7 & 1 & 6 & 0 & 0 & 0 & I & 2 & 0 \\
\hline Chen et $\mathrm{al}^{89}$ & 18 & $\mathrm{I}$ & 17 & 0 & 0 & 2 & 3 & - & - \\
\hline Luo et $\mathrm{al}^{24}$ & 14 & 0 & 14 & - & - & 0 & I & 0 & 11 \\
\hline Gaynor et al ${ }^{83}$ & 15 & 15 & 0 & 4 & 0 & - & - & $\mathrm{I}$ & 9 \\
\hline Miller et $\mathrm{al}^{78}$ & 5 & 5 & 0 & 4 & 0 & - & - & 0 & I \\
\hline Lee et $\mathrm{a}^{82}$ & 25 & 0 & 25 & - & - & 4 & - & 4 & - \\
\hline Chaloupka et al ${ }^{68}$ & 14 & 0 & 14 & - & - & 2 & 0 & 2 & - \\
\hline Chang et $\mathrm{al}^{69}$ & 56 & 18 & 38 & 7 & 3 & 5 & 6 & - & - \\
\hline Manzoor et al ${ }^{76}$ & 9 & 2 & 7 & $\mathrm{I}$ & 0 & 0 & $\mathrm{I}$ & - & - \\
\hline Zussman et $\mathrm{al}^{84}$ & 6 & 0 & 6 & - & - & I & 0 & 2 & 0 \\
\hline Chen et $\mathrm{al}^{60}$ & 13 & 13 & 0 & 4 & 0 & - & - & 5 & 2 \\
\hline Chang et al' & 24 & 11 & 13 & 5 & 1 & 3 & I & 4 & 6 \\
\hline Patsalides et $\mathrm{al}^{71}$ & 8 & 5 & 3 & $\mathrm{I}$ & 0 & 0 & $\mathrm{I}$ & 2 & 2 \\
\hline Lesley et $\mathrm{al}^{80}$ & 9 & 9 & 0 & 3 & 0 & - & - & I & 3 \\
\hline Morrissey et $\mathrm{al}^{65}$ & 12 & 0 & 12 & - & - & 0 & I & - & - \\
\hline Roh et al ${ }^{66}$ & 11 & 5 & 6 & 2 & 1 & 2 & 2 & 2 & 2 \\
\hline Sorial et $\mathrm{a}^{81}$ & 4 & 4 & 0 & I & 0 & - & - & 2 & 0 \\
\hline Wan et $a^{88}$ & 14 & 4 & 10 & 2 & 1 & I & 1 & 4 & 5 \\
\hline Zhao et al ${ }^{70}$ & 15 & 10 & 5 & 4 & 3 & 1 & 0 & - & 3 \\
\hline Hakime et a ${ }^{73}$ & 20 & 20 & 0 & 5 & 0 & - & - & 5 & 4 \\
\hline Liang et $\mathrm{al}^{22}$ & 25 & 11 & 14 & 3 & 1 & 3 & 2 & 12 & 13 \\
\hline Pyun et $\mathrm{al}^{79}$ & 7 & 7 & 0 & 6 & 0 & - & - & 5 & 0 \\
\hline Lu et $\mathrm{al}^{7}$ & 30 & 3 & 27 & 0 & 1 & 6 & 2 & - & - \\
\hline Hoppe et $\mathrm{al}^{75}$ & 13 & 13 & 0 & 3 & 0 & - & - & 2 & 4 \\
\hline Total & 429 & $\begin{array}{l}177 \\
41 \%\end{array}$ & $\begin{array}{l}252 \\
59 \%\end{array}$ & $\begin{array}{l}63 \\
36 \%\end{array}$ & $\begin{array}{l}14 \\
8 \%\end{array}$ & $\begin{array}{l}42 \\
17 \%\end{array}$ & $\begin{array}{l}29 \\
12 \%\end{array}$ & $\begin{array}{l}72 \\
17 \%\end{array}$ & $\begin{array}{l}72 \\
17 \%\end{array}$ \\
\hline
\end{tabular}

Abbreviations: CBS, carotid blowout syndrome; Compl stent, complications stent; Compl embol, complications embolization; Emb, embolization; Rbl, rebleeding.

persistent endoluminal leakage or involvement of the carotid artery with tumor either proximal or distal to the stent, as well as due to erosion of the arterial wall by the stent. Existence of an uncontrolled ongoing infection at the stent site is an important factor associated with recurrent CBS. ${ }^{79}$ Hakime et al reported that 6 of 20 patients with recurrent CBS had no identifiable source of bleeding on previous angiography but demonstrated a threatened carotid axis on computed tomography. ${ }^{73}$ In these cases, precise targeted therapy could not be performed, excluding the bleeding lesion. As stated by Huvos et al, radiation therapy, infection and tumor recurrence give rise to vessel modifications with weakening of the arterial wall extending several centimeters. ${ }^{87}$ Considerable variability in intervals between episodes of recurrent CBS have been observed, ranging from 1 day to 6 years. ${ }^{28}$ Chaloupka et al differentiate recurrent events attributable to progressive disease from those attributable to treatment failures. ${ }^{28}$ Whatever the cause may be, most can be successfully managed by additional stent grafts, coil embolization or excising the diseased segment and replacing it with a vein graft, with a mortality rate in the range of $10 \%-30 \%{ }^{28,60}$

Incomplete stent apposition to the inner wall of the carotid bulb leaves a potential gap for an endoleak, which could lead to potentially life-threatening rebleeding in acute CBS. ${ }^{60}$ Endoluminal leakage has been seen in $27 \%-92 \%$ of patients with covered stents.

Other complications, both in the stent and embolization patients, include septic thrombosis with multiple brain abscesses, neck abscess formation and extrusion of the stent or the coils for embolization. ${ }^{1,69,70,88}$

\section{Outcomes of endovascular procedures}

Patients suffering from CBS are in advanced stages of head and neck cancer, have often had recurrent disease, received 
different aggressive treatments and generally show high levels of comorbidity. All of this implies an adverse prognosis. Therefore, the most common cause of mortality for patients who have survived CBS is disease progression rather than related complications, the long-term progression-free survival of CBS patients being similar to those of patients without CBS. ${ }^{7}$

In a survey of 1,218 patients who underwent endovascular treatment for CBS, Brinjikji et al have reported an overall in-hospital mortality rate of $8.2 \%$ for patients receiving endovascular treatment for CBS, with no differences for patients undergoing endovascular embolization $(8.0 \%)$ or carotid stenting $(10.1 \%) .{ }^{67}$ The reported mean time from initial CBS to death has ranged from 4 to 12 months, ${ }^{1,66,87}$ with no differences between patients managed with embolization or stenting. ${ }^{1}$ Finally, $<10 \%$ of patients exceed 3 years of survival after CBS. ${ }^{66,70,75,87,89}$

\section{Conclusion}

CBS following head and neck surgery is less frequent than in the past because reconstructive techniques using well-vascularized flaps are now standard, but carries important consequences in terms of mortality and morbidity. It usually occurs in patients with advanced or recurrent tumors that have required aggressive treatment. The most important risk factor for CBS after surgery is previous irradiation of the neck, and in cases of reirradiation involvement of the carotid artery by tumor.

Endovascular techniques are now the standard of care, but in cases of acute bleeding in the presence of fistula and advanced necrosis surgical ligation may be necessary.

In patients who survive a CBS event, the prognosis usually depends on the course of the malignancy.

\section{Ethical approval}

This article does not contain any studies with human participants or animals performed by any of the authors.

\section{Acknowledgment}

This article was written by members and invitees of the International Head and Neck Scientific Group (www.IHNSG. $\underline{\mathrm{com}})$.

\section{Disclosure}

The authors report no conflicts of interest in this work.

\section{References}

1. Chang FC, Lirng JF, Luo CB, et al. Patients with head and neck cancers and associated postirradiated carotid blowout syndrome: endovascular therapeutic methods and outcomes. J Vasc Surg. 2008;47(5):936-945.

2. Leikensohn J, Milko D, Cotton R. Carotid artery rupture. Management and prevention of delayed neurologic sequelae with low-dose heparin. Arch Otolaryngol. 1978;104(6):307-310.
3. Shumrick DA. Carotid artery rupture. Laryngoscope. 1973;83(7): 1051-1061.

4. Martinez SA, Oller DW, Gee W, de Fries HO. Elective carotid artery resection. Arch Otolaryngol. 1975;101(12):744-747.

5. Ketcham AS, Hoye RC. Spontaneous carotid artery hemorrhage after head and neck surgery. Am J Surg. 1965;110(4):649-655.

6. McCoy G, Barsocchini LM. Experiences in carotid artery occlusion. Laryngoscope. 1968;78(7):1195-1210.

7. Lu HJ, Chen KW, Chen MH, et al. Predisposing factors, management, and prognostic evaluation of acute carotid blowout syndrome. $J$ Vasc Surg. 2013;58(5):1226-1235.

8. Joseph DL, Shumrick DL. Risks of head and neck surgery in previously irradiated patients. Arch Otolaryngol. 1973;97(5):381-384.

9. Curutchet HP, Terz JJ, Lawrence W Jr. The value of the autogenous dermal graft for carotid artery protection. Surgery. 1972;71(6):876-880.

10. Yim D, Rappaport I, Jose L, Kohut R, Shramek J. Carotid artery and dermal graft. Arch Otolaryngol. 1974;99(4):242-246.

11. Stell PM. Catastrophic haemorrhage after major neck surgery. $\mathrm{Br} J$ Surg. 1969;56(7):525-527.

12. Maran AG, Amin M, Wilson JA. Radical neck dissection: a 19-year experience. J Laryngol Otol. 1989;103(8):760-764.

13. Marchetta FC, Sako K, Maxwell W. Complications after radical head and neck surgery performed through previously irradiated tissues. $\mathrm{Am}$ J Surg. 1967;114(6):835-838.

14. Sarkar S, Mehta SA, Tiwari J, Mehta AR, Mehta MS. Complications following surgery for cancer of the larynx and pyriform fossa. $J$ Surg Oncol. 1990;43(4):245-249.

15. Herranz J, Sarandeses A, Fernández MF, Barro CV, Vidal JM, Gavilán J. Complications after total laryngectomy in nonradiated laryngeal and hypopharyngeal carcinomas. Otolaryngol Head Neck Surg. 2000;122(6):892-898.

16. Gall AM, Sessions DG, Ogura JH. Complications following surgery for cancer of the larynx and hypopharynx. Cancer. 1977;39(2):624-631.

17. Krause CJ, Smits RG, McCabe BF. Complications associated with combined therapy of oral and pharyngeal neoplasms. Ann Otol Rhinol Laryngol. 1972;81(4):496-500.

18. Macdonald S, Gan J, McKay AJ, Edwards RD. Endovascular treatment of acute carotid blow-out syndrome. J Vasc Interv Radiol. 2000;11(9):1184-1188.

19. Heller KS, Strong EW. Carotid arterial hemorrhage after radical head and neck surgery. Am J Surg. 1979;138(4):607-610.

20. Powitzky R, Vasan N, Krempl G, Medina J. Carotid blowout in patients with head and neck cancer. Ann Otol Rhinol Laryngol. 2010;119(7):476-484.

21. Razack MS, Sako K. Carotid artery hemorrhage and ligation in head and neck cancer. J Surg Oncol. 1982;19(4):189-192.

22. Liang NL, Guedes BD, Duvvuri U, et al. Outcomes of interventions for carotid blowout syndrome in patients with head and neck cancer. J Vasc Surg. 2016;63(6):1525-1530.

23. Upile T, Triaridis S, Kirkland P, et al. The management of carotid artery rupture. Eur Arch Otorhinolaryngol. 2005;262(7):555-560.

24. Luo CB, Teng MM, Chang FC, Chang CY, Guo WY. Radiation carotid blowout syndrome in nasopharyngeal carcinoma: angiographic features and endovascular management. Otolaryngol Head Neck Surg. 2008;138(1):86-91.

25. Chen YJ, Wang CP, Wang CC, Jiang RS, Lin JC, Liu SA. Carotid blowout in patients with head and neck cancer: associated factors and treatment outcomes. Head Neck. 2015;37(2):265-272.

26. Ernemann U, Herrmann C, Plontke S, Schäfer J, Plasswilm L, Skalej M. Pseudoaneurysm of the superior thyroid artery following radiotherapy for hypopharyngeal cancer. Ann Otol Rhinol Laryngol. 2003;112(2):188-190.

27. Swain RE, Biller HF, Ogura JH, Harvey JE. An experimental analysis of causative factors and protective methods in carotid artery rupture. Arch Otolaryngol. 1974;99(4):235-241.

28. Chaloupka JC, Roth TC, Putman CM, et al. Recurrent carotid blowout syndrome: diagnostic and therapeutic challenges in a newly recognized subgroup of patients. AJNR Am J Neuroradiol. 1999;20(6):1069-1077. 
29. Pathak KA, Viallet NR, Nason RW. Sternocleidomastoid muscle interposition to prevent carotid artery blowout. J Surg Oncol. 2008;98(7):565-566

30. Cordova A, D’Arpa S, Di Lorenzo S, Toia F, Campisi G, Moschella F. Prophylactic chimera anterolateral thigh/vastus lateralis flap: preventing complications in high-risk head and neck reconstruction. J Oral Maxillofac Surg. 2014;72(5):1013-1022.

31. Dawson LA, Myers LL, Bradford CR, et al. Conformal re-irradiation of recurrent and new primary head-and-neck cancer. Int J Radiat Oncol Biol Phys. 2001;50(2):377-385.

32. Kasperts N, Slotman BJ, Leemans CR, de Bree R, Doornaert P, Langendijk JA. Results of postoperative reirradiation for recurrent or second primary head and neck carcinoma. Cancer. 2006;106(7):1536-1547.

33. Tanvetyanon T, Padhya T, McCaffrey J, et al. Prognostic factors for survival after salvage reirradiation of head and neck cancer. J Clin Oncol. 2009;27(12):1983-1991.

34. Rate WR, Garrett P, Hamaker R et al. Intraoperative radiation therapy for recurrent head and neck cancer. Cancer. 1991;67(11) 2738-2740.

35. Stevens KR Jr, Britsch A, Moss WT. High-dose reirradiation of head and neck cancer with curative intent. Int J Radiat Oncol Biol Phys. 1994;29(4):687-698.

36. Duprez F, Madani I, Bonte K, et al. Intensity-modulated radiotherapy for recurrent and second primary head and neck cancer in previously irradiated territory. Radiother Oncol. 2009;93(3):563-569.

37. Lee N, Chan K, Bekelman JE, et al. Salvage re-irradiation for recurrent head and neck cancer. Int J Radiat Oncol Biol Phys. 2007;68(3): 731-740.

38. Sulman EP, Schwartz DL, Le TT, et al. IMRT reirradiation of head and neck cancer-disease control and morbidity outcomes. Int J Radiat Oncol Biol Phys. 2009;73(2):399-409.

39. Watkins JM, Shirai KS, Wahlquist AE, et al. Toxicity and survival outcomes of hyperfractionated split-course reirradiation and daily concurrent chemotherapy in locoregionally recurrent, previously irradiated head and neck cancers. Head Neck. 2009;31(4):493-502.

40. De Crevoisier R, Bourhis J, Domenge C, et al. Full-dose reirradiation for unresectable head and neck carcinoma: experience at the Gustave-Roussy Institute in a series of 169 patients. J Clin Oncol. 1998;16(11):3556-3562.

41. Salama JK, Vokes EE, Chmura SJ, et al. Long-term outcome of concurrent chemotherapy and reirradiation for recurrent and second primary head-and-neck squamous cell carcinoma. Int J Radiat Oncol Biol Phys. 2006;64(2):382-391

42. Janot F, de Raucourt D, Benhamou E, et al. Randomized trial of postoperative reirradiation combined with chemotherapy after salvage surgery compared with salvage surgery alone in head and neck carcinoma. $J$ Clin Oncol. 2008;26(34):5518-5523.

43. Kramer NM, Horwitz EM, Cheng J, et al. Toxicity and outcome analysis of patients with recurrent head and neck cancer treated with hyperfractionated split-course reirradiation and concurrent cisplatin and paclitaxel chemotherapy from two prospective phase I and II studies. Head Neck. 2005;27(5):406-414.

44. Langer CJ, Harris J, Horwitz EM, et al. Phase II study of low-dose paclitaxel and cisplatin in combination with split-course concomitant twice-daily reirradiation in recurrent squamous cell carcinoma of the head and neck: results of Radiation Therapy Oncology Group Protocol 9911. J Clin Oncol. 2007;25(30):4800-4805.

45. Spencer SA, Harris J, Wheeler RH, et al. Final report of RTOG 9610, a multi-institutional trial of reirradiation and chemotherapy for unresectable recurrent squamous cell carcinoma of the head and neck. Head Neck. 2008;30(3):281-288.

46. Hehr T, Classen J, Belka C, et al. Reirradiation alternating with docetaxel and cisplatin in inoperable recurrence of head-and-neck cancer: a prospective phase I/II trial. Int J Radiat Oncol Biol Phys. 2005;61(5):1423-1431.
47. Iseli TA, Iseli CE, Rosenthal EL, et al. Postoperative reirradiation for mucosal head and neck squamous cell carcinomas. Arch Otolaryngol Head Neck Surg. 2009;135(11):1158-1164.

48. Lartigau EF, Tresch E, Thariat J, et al. Multi institutional phase II study of concomitant stereotactic reirradiation and cetuximab for recurrent head and neck cancer. Radiother Oncol. 2013;109(2):281-285.

49. Cengiz M, Özyiğit G, Yazici G, et al. Salvage reirradiaton with stereotactic body radiotherapy for locally recurrent head-and-neck tumors. Int J Radiat Oncol Biol Phys. 2011;81(1):104-109.

50. Yamazaki H, Ogita M, Kodani N, et al. Frequency, outcome and prognostic factors of carotid blowout syndrome after hypofractionated re-irradiation of head and neck cancer using CyberKnife: a multiinstitutional study. Radiother Oncol. 2013;107(3):305-309.

51. Yazici G, Sanlı TY, Cengiz M, et al. A simple strategy to decrease fatal carotid blowout syndrome after stereotactic body reirradiaton for recurrent head and neck cancers. Radiat Oncol. 2013;8:242.

52. Vargo JA, Ferris RL, Ohr J, et al. A prospective phase 2 trial of reirradiation with stereotactic body radiation therapy plus cetuximab in patients with previously irradiated recurrent squamous cell carcinoma of the head and neck. Int J Radiat Oncol Biol Phys. 2015;91(3):480-488.

53. McDonald MW, Moore MG, Johnstone PA. Risk of carotid blowout after reirradiation of the head and neck: a systematic review. Int $J$ Radiat Oncol Biol Phys. 2012;82(3):1083-1089.

54. Schaefer U, Micke O, Schueller P, Willich N. Recurrent head and neck cancer: retreatment of previously irradiated areas with combined chemotherapy and radiation therapy-results of a prospective study. Radiology. 2000;216(2):371-376

55. Suh JD, Kim BP, Abemayor E, et al. Reirradiation after salvage surgery and microvascular free flap reconstruction for recurrent head and neck carcinoma. Otolaryngol Head Neck Surg. 2008;139(6):781-786.

56. Langlois D, Eschwege F, Kramar A, Richard JM. Reirradiation of head and neck cancers. Radiother Oncol. 1985;3(1):27-33.

57. Liu HM, Yang CY, Lee CW, Wang YH, Chen YF. Rapid, sequential bilateral acute carotid blowout syndrome. Neuroradiology. 2013;55(4):475-481.

58. Yamazaki H, Ogita M, Himei K, et al. Carotid blowout syndrome in pharyngeal cancer patients treated by hypofractionated stereotactic re-irradiation using CyberKnife: a multi-institutional matched-cohort analysis. Radiother Oncol. 2015;115(1):67-71.

59. Esteller E, León X, de Juan M, Quer M. Delayed carotid blow-out syndrome: a new complication of chemoradiotherapy treatment in pharyngolaryngeal carcinoma. J Laryngol Otol. 2012;126(11):1189-1191.

60. Chen YL, Wong HF, Ku YK, Wong AM, Wai YY, Ng SH. Endovascular covered stent reconstruction improved the outcomes of acute carotid blowout syndrome. Experiences at a single institute. Interv Neuroradiol. 2008;14(Suppl 2):23-27.

61. Coleman JJ 3rd. Treatment of the ruptured or exposed carotid artery: a rational approach. South Med J. 1985;78(3):262-267.

62. Porto DP, Adams GL, Foster C. Emergency management of carotid artery rupture. Am J Otolaryngol. 1986;7(3):213-217.

63. Citardi MJ, Chaloupka JC, Son YH, Ariyan S, Sasaki CT. Management of carotid artery rupture by monitored endovascular therapeutic occlusion (1988-1994). Laryngoscope. 1995;105(10):1086-1092.

64. Moore OS, Karlan M, Sigler L. Factors influencing the safety of carotid ligation. Am J Surg. 1969;118(5):666-668.

65. Morrissey DD, Andersen PE, Nesbit GM, Barnwell SL, Everts EC, Cohen JI. Endovascular management of hemorrhage in patients with head and neck cancer. Arch Otolaryngol Head Neck Surg. 1997;123(1):15-19.

66. Roh JL, Suh DC, Kim MR, et al. Endovascular management of carotid blowout syndrome in patients with head and neck cancers. Oral Oncol. 2008;44(9):844-850.

67. Brinjikji W, Cloft HJ. Outcomes of endovascular occlusion and stenting in the treatment of carotid blowout. Interv Neuroradiol. 2015;21(4):543-547. 
68. Chaloupka JC, Putman CM, Citardi MJ, Ross DA, Sasaki CT. Endovascular therapy for the carotid blowout syndrome in head and neck surgical patients: diagnostic and managerial considerations. AJNR Am J Neuroradiol. 1996;17(5):843-852.

69. Chang FC, Luo CB, Lirng JF, et al. Endovascular management of postirradiated carotid blowout syndrome. PLoS One. 2015;10(10):e139821.

70. Zhao LB, Shi HB, Park S, et al. Acute bleeding in the head and neck: angiographic findings and endovascular management. AJNR Am J Neuroradiol. 2014;35(2):360-366.

71. Patsalides A, Fraser JF, Smith MJ, Kraus D, Gobin YP, Riina HA. Endovascular treatment of carotid blowout syndrome: who and how to treat. J Neurointerv Surg. 2010;2(1):87-93.

72. Shankar JJ, Maloney WJ, Vandorpe R. Amplatzer vascular plug for occlusion of parent artery in carotid blowout with active extravasation. Interv Neuroradiol. 2011;17(2):224-227.

73. Hakime A, Khoury E, Hameg A, et al. Polytetrafluoroethylene-covered nitinol stent graft for treatment of carotid artery blowout syndrome in head and neck cancer patients. Laryngoscope. 2013;123(7):1670-1675.

74. Gaba RC, West DL, Bui JT, Owens CA, Marden FA. Covered stent treatment of carotid blowout syndrome. Semin Intervent Radiol. 2007;24(1): 47-52.

75. Hoppe H, Barnwell SL, Nesbit GM, Petersen BD. Stent-grafts in the treatment of emergent or urgent carotid artery disease: review of 25 cases. J Vasc Interv Radiol. 2008;19(1):31-41.

76. Manzoor NF, Rezaee RP, Ray A, et al. Contemporary management of carotid blowout syndrome utilizing endovascular techniques. Laryngoscope. 2017;127(2):383-390.

77. Bond KM, Brinjikji W, Murad MH, Cloft HJ, Lanzino G. Endovascular treatment of carotid blowout syndrome. JVasc Surg. 2017;65(3):883-888.

78. Miller T, Burns J, Farinhas J, et al. Covered stents safely utilized to prevent catastrophic hemorrhage in patients with advanced head and neck malignancy. J Neurointerv Surg. 2012;4(6):426-434.

79. Pyun HW, Lee DH, Yoo HM, et al. Placement of covered stents for carotid blowout in patients with head and neck cancer: follow-up results after rescue treatments. AJNR Am J Neuroradiol. 2007;28(8):1594-1598.
80. Lesley WS, Chaloupka JC, Weigele JB, Mangla S, Dogar MA. Preliminary experience with endovascular reconstruction for the management of carotid blowout syndrome. AJNR Am J Neuroradiol. 2003;24(5):975-981.

81. Sorial E, Valentino J, Given CA, Endean ED, Minion DJ. The emergency use of endografts in the carotid circulation to control hemorrhage in potentially contaminated fields. J Vasc Surg. 2007;46(4):792-798.

82. Lee CW, Yang CY, Chen YF, Huang A, Wang YH, Liu HM. CT angiography findings in carotid blowout syndrome and its role as a predictor of 1-year survival. AJNR Am J Neuroradiol. 2014;35(3): $562-567$.

83. Gaynor BG, Haussen DC, Ambekar S, Peterson EC, Yavagal DR, Elhammady MS. Covered stents for the prevention and treatment of carotid blowout syndrome. Neurosurgery. 2015;77(2):164-167.

84. Zussman B, Gonzalez LF, Dumont A, et al. Endovascular management of carotid blowout. World Neurosurg. 2012;78(1-2):109-114.

85. Chang FC, Lirng JF, Luo CB, et al. Carotid blowout syndrome in patients with head-and-neck cancers: reconstructive management by self-expandable stent-grafts. AJNR Am J Neuroradiol. 2007;28(1): 181-188.

86. Shah H, Gemmete JJ, Chaudhary N, Pandey AS, Ansari SA. Acute life-threatening hemorrhage in patients with head and neck cancer presenting with carotid blowout syndrome: follow-up results after initial hemostasis with covered-stent placement. AJNR Am J Neuroradiol. 2011;32(4):743-747.

87. Huvos AG, Leaming RH, Moore OS. Clinicopathologic study of the resected carotid artery. Analysis of sixty-four cases. Am J Surg. 1973;126(4):570-574.

88. Wan WS, Lai V, Lau HY, Wong YC, Poon WL, Tan CB. Endovascular treatment paradigm of carotid blowout syndrome: review of 8-years experience. Eur J Radiol. 2013;82(1):95-99.

89. Chen KC, Yen TT, Hsieh YL, et al. Postirradiated carotid blowout syndrome in patients with nasopharyngeal carcinoma: a case-control study. Head Neck. 2015;37(6):794-799.
Cancer Management and Research

\section{Publish your work in this journal}

Cancer Management and Research is an international, peer-reviewed open access journal focusing on cancer research and the optimal use of preventative and integrated treatment interventions to achieve improved outcomes, enhanced survival and quality of life for the cancer patient. The manuscript management system is completely online and includes

\section{Dovepress}

a very quick and fair peer-review system, which is all easy to use. Visi $\mathrm{http}: / / \mathrm{www}$.dovepress.com/testimonials.php to read real quotes from published authors. 